This is an open access article under the CC BY-NC-ND license (https://creativecommons.org/licenses/by-nc-nd/3.0/) Issue III, November 2020

ISSN 2707-9481

ISBN 978-601-323-207-2

https://doi.org/10.31643/2020.029

\section{Ulugbek Ruziev}

Institute of General and Inorganic Chemistry of the Academy of Sciences of the Republic of Uzbekistan, Uzbekistan. Email: ionxanruz@mail.ru

ORCID ID https://orcid.org/0000-0002-8395-7750

\section{Umid Ernazarov}

Institute of General and Inorganic Chemistry of the Academy of Sciences of the Republic of Uzbekistan, Uzbekistan. Email: ionxanruz@mail.ru ORCID ID https://orcid.org/0000-0002-9610-0334

\author{
Vitaliy P. Guro \\ Institute of General and Inorganic Chemistry of the Academy \\ of Sciences of the Republic of Uzbekistan, Uzbekistan \\ Email: ionxanruz@mail.ru \\ ORCID ID https://orcid.org/0000-0001-5765-0408
}

\title{
Alloying Hard Metals of Tungsten Carbide-Cobalt System with Vanadium and Rhenium to Improve Wear Resistance
}

\begin{abstract}
Vanadium and rhenium modified samples of hard alloy systems WC-VC-Co, WC-ReC-Co (grade VK-6) are considered when testing their wear resistance and hardness, in comparison with the serial alloy VK-6. The samples of the groups differed in the content of vanadium and rhenium, and additional purification of the raw material. The reason for the reduced wear resistance of the VK-6 alloy, caused by the structural features and the presence of impurities, is revealed. Sample test results: WC-VC-Co alloys in the VC concentration range of 1.0-16.0\% by weight, turned out to be $\approx 3 \%$ harder and 30-90\% more resistant to wear; WC-ReC-Co alloys, at a ReC concentration of $1-5 \%$ by weight, turned out to be $\approx 3 \%$ harder and $38.5 \%$ more resistant to wear; additional purification of the $\mathrm{W}$-raw material of the WC-ReC-Co alloy with a ReC concentration of $5 \%$ by weight, in comparison with the alloys: VK-6 and VK-6 modified with 5\% rhenium without additional purification, increased wear resistance from 38.5\% (alloy "VK-6 modified with 5\% rhenium"), up to $57.0 \%$ (single) and $65.3 \%$ (three times purification) alloy "VK-6 modified with 5\% rhenium with additional purification". Experimental-industrial tests of products - surfacing on turning tools made of VK-6 alloy with VC 3\% wt., Revealed that they were 30-35\% more resistant to wear than samples from the serial VK-6 alloy, with an equal content cobalt; this means an increase in the resource of the tool by 30-35\%. It was recommended to introduce alloying and additional purification of tungsten raw materials.
\end{abstract}

Keywords: hard alloy, tungsten carbide, cobalt, vanadium carbide, rhenium, wear resistance, strength, hardness.

Cite this article as: Ruziev U., Ernazarov U., Guro V. P. (2020). Legirovaniye Tverdykh Splavov Sistemy Karbid Vol'frama-Kobal't Vanadiyem i Reniyem Dlya Povysheniya Iznosostoykosti [Alloying Hard Metals of Tungsten Carbide-Cobalt System with Vanadium and Rhenium to Improve Wear Resistance]. Challenges of Science. Issue III, p.: 190-194. (In Russian). https://doi.org/10.31643/2020.029

\section{Улугбек Рузиев}

Институт общей и неорганической химии Академии наук Республики Узбекистан,

Узбекистан. Email: ionxanruz@mail.ru ORCID ID https://orcid.org/0000-0002-8395-7750

\section{Умид Эрназаров}

Институт общей и неорганической химии Академии наук Республики Узбекистан,

Узбекистан. Email: ionxanruz@mail.ru ORCID ID https://orcid.org/0000-0002-9610-0334 
Виталий П. Гуро

Институт общей и неорганической химии Академии наук

Республики Узбекистан, Узбекистан

Email: ionxanruz@mail.ru

ORCID ID https://orcid.org/0000-0001-5765-0408

\title{
Легирование Твердых Сплавов Системы Карбид Вольфрама- Кобальт Ванадием и Рением Для Повышения Износостойкости
}

\begin{abstract}
Абстракт. Рассмотрены модифицированные ванадием и рением образцы твердого сплава систем WC$\mathrm{VC}-\mathrm{Co}$, WC-ReC-Co (марки ВК-6) при испытании их износостойкости и твердости, сравнительно с серийным сплавом ВК-6. Образцы групп отличались содержанием ванадия и рения, и дополнительной очисткой сырья. Выявлена причина пониженной износостойкости сплава ВК-6, вызванная структурными особенностями и наличием примесей. Результаты испытаний образцов: сплавы WC-VC-Cо в диапазоне концентрации VC 1,0$16,0 \%$ масс., оказались, на $\approx 3 \%$ более твердыми и на 30-90\% более стойкими к износу; сплавы WC-ReC-Co, при концентрации $\operatorname{ReC} 1-5 \%$ масс., оказались на $\approx 3 \%$ более твердыми и на $38,5 \%$ более стойкими к износу; дополнительная очистка W-сырья сплава WC-ReC-Co с концентрацией $\mathrm{ReC} 5 \%$ масc., по сравнению со сплавами: «ВК-6» и «ВК-6 модифицированный 5\% рения без дополнительной очистки», повысила износостойкость с $38,5 \%$ (сплав «ВК-6 модифицированный 5\% рения»), до 57,0\% (однократная) и 65,3\% (трехкратная очистка) сплава «ВК-6 модифицированный $5 \%$ рения с дополнительной очисткой». Проведенные опытно-промышленные испытания изделий - наплавок на токарные резцы из сплава ВК-6 с VC 3\% масс., выявили, что они оказались на $30-35 \%$ более стойкими к износу, чем образцы из серийного сплава ВК-6, с равным содержанием кобальта; это означает увеличение ресурса работы инструмента на 30-35\%. Рекомендовано внедрить легирование и дополнительную очистку вольфрамового сырья.
\end{abstract}

Ключевые слова: твердый сплав, карбид вольфрама, кобальт, карбид ванадия, рения, износостойкость, прочность, твердость.

\section{Введение}

НПО АО «Алмалыкский ГМК» располагает собственным товарным рением, образуемом при переработке Мо-концентрата (Rasulova, S.N., Guro, V.P., Safarov, E.T., Adinaev, X.F., 2020). [1]. Целесообразно использовать его, наряду с ванадием, для легирования твердых сплавов, которые не удовлетворяют потребителя по своим эксплуатационным свойствам. Повысить ресурс бурового и станочного инструмента из них - актуальная задача НПО АО «Алмалыкский ГМК». Решение ее возможно на пути создания технологии структурирования и легирования твердых сплавов системы «карбид вольфрама-кобальт» компонентами, повышающими их прочность к истиранию. Пока же твердый сплав ВК-6, в практике буровых, землепроходческих работ, использования режущих кромок станочного инструмента обнаруживает, в сравнении с импортными аналогами, пониженные износостойкие свойства. Возможные причины этого феномена следующие:

- неоптимизированная структура компонентов сплава;

- нежелательные примеси в сырье;

- возможное легирование импортных аналогов.

Имеются сообщения об эффективности легировании ванадием твердых сплавов системы $\mathrm{WC}-$ $\mathrm{Co}$, в диапазоне концентраций 1-12 вес. \%. Получаемый сплав не теряет твердость, характерную для ультрадисперсных систем WC-Co. Плотность материалов WC-VC-Co ниже, чем у WC-Co с равным содержанием Со. Плотность карбидов VC и $\mathrm{WC}$ равна 5,57 и $15.6 \mathrm{~g} \cdot \mathrm{cm}^{-3}$, соответственно, a $(\mathrm{W}, \mathrm{V}) \mathrm{C}$ сплавов: 11-12 g.cm ${ }^{-3}$. Микротвердость фаз $\mathrm{V}_{8} \mathrm{C}_{7}$ и $\mathrm{WC}$, по Виккерсу: 2900 и $2000 \mathrm{HV}$. Прочность по Пальквисту тонкодисперсных WC-VC-Cо сплавов или равна, или выше, чем у WC-Co-сплавов той же объемной доли Co, но выше, чем у сверхтонких WC-Со равной твердости (du Randt, D., Luyckz, S., Marcoulides, D., Northrop, I.T. and Whitefield, D.J., 2000) [2].

Объект исследования - компоненты и сырье производства сплава ВК-6, пентоксид ванадия. 


\section{Цель работы}

Разработать технологию получения твердого сплава нового поколения системы WC-VC-Co, повышенной износостойкости, с выбором оптимальной доли $\mathrm{VC}$, в диапазоне 1-12\%.

\section{Результаты и их обсуждение}

Контроль химического состава образцов выполнен на AAC- и ICP-спектрометрах: Perkin-Elmer 3030B, Aligent 7500 ICP MS. Контроль поверхности твердых сплавов осуществлялся в Центре высоких технологий на сканирующем электронном микроскопе ZEISS EVO MA 10, Carl Zeiss Group, с увеличением до 1000000 крат, разрешением до 0,4 нм, с детектором рентгеноспектрального микроэлементного анализа. Рентгенофазовый контроль - на рентгеновском дифрактометре EMPYREAN XDR c измерениями «на просвет», с зондом элементного анализа рентгенофлюоресценцией. Испытания износостойкости выполнены на пилотной установке, твердости по Роквеллу HRA - в НПО АО «Алмалыкский ГМК». На 1-м этапе синтезированы 4 образца ВК-6, с заменой $1 \% \mathrm{WC}$ на $1 \% \mathrm{VC}$; проведены сравнительные измерения микротвердости по Роквеллу и износостойкости, выполнена их электронная микроскопия (рис. 1-2).

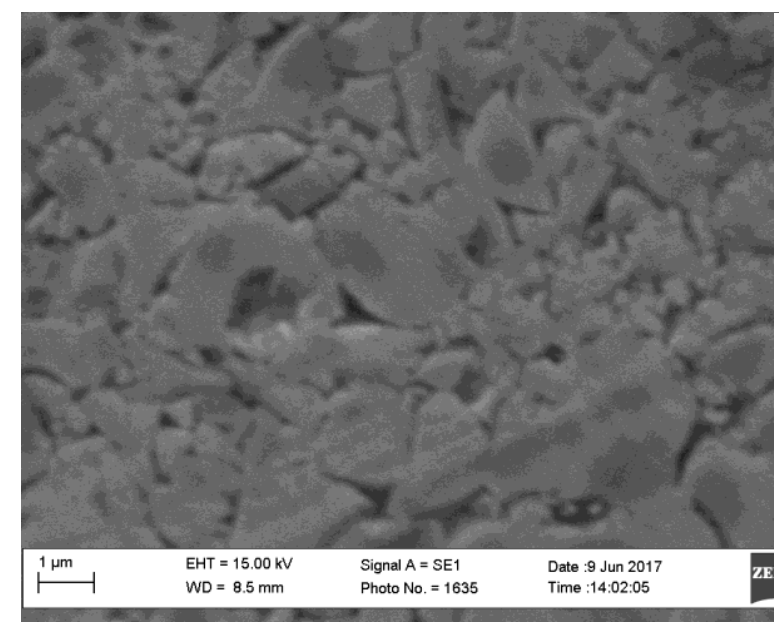

Рис. 1. Вид поверхности образца №1 (без ванадия)

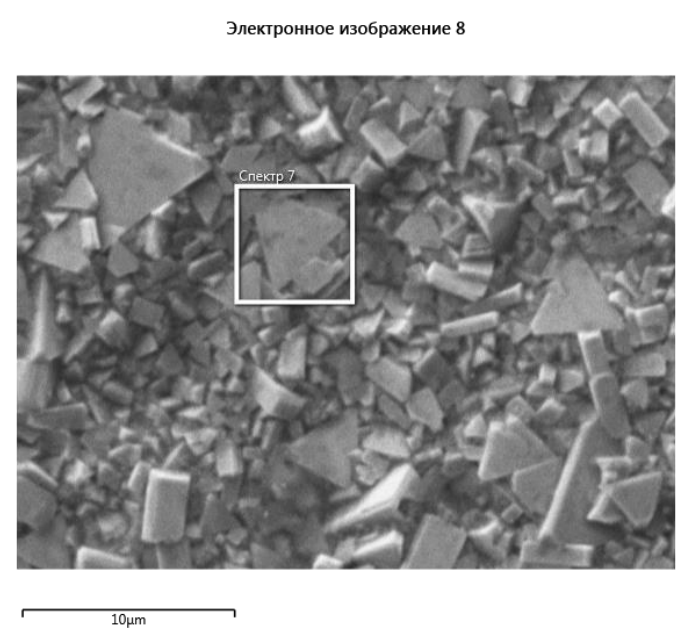

Рис. 2. Вид поверхности образца №2 (с ванадием)

Регламентом исследования предусмотрены 3 задания: легирование ванадием; легирование рением; использование вольфрамового сырья повышенной степени очистки. Все образцы испытаны относительно сплава ВК-6. По заданию 1 изготовлены и испытаны на твердость и износ WC-VC-Co образцы (рис. 3). По заданию 2 - WC-ReC-Co образцы (таблица 1). По заданию 3 - образцы «ВК-6модифицированный 5\% рения с дополнительной очисткой» (таблицы 1 и 2).

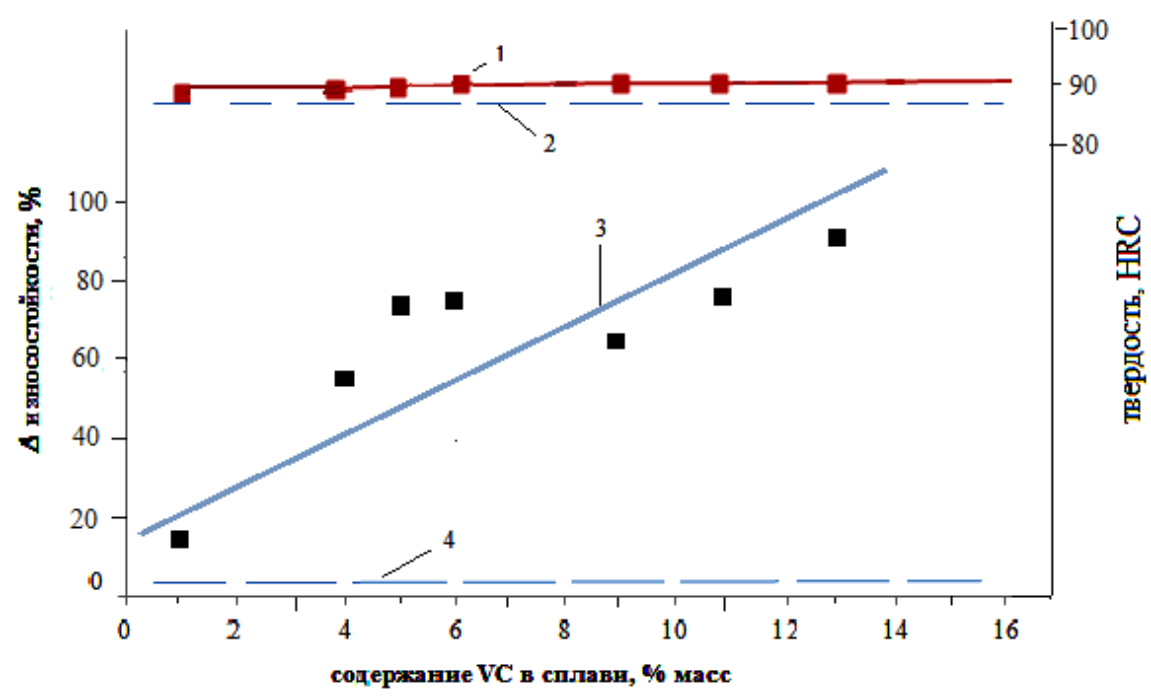

Рис. 3. Данные о твердости и износостойкости образцов (Задание №1) 
Установлено, что у нелегированных образцов HRA 88,5; у легированных ванадием HRA 88,7, то есть, введение $1 \%$ VC повышает твердость. Показано, что легирование $1 \%$ карбидом ванадия сплава ВК-6 повышает его износостойкость на 17-29\%. Проведено исследование поверхности образцов, показавшее, что введение в сплав добавки ванадия ингибирует рост зерна сплава, способствуя его нано-структурированию. На втором этапе выполнено повторный синтез модифицированных ванадием и рением образцов сплава ВК-6 в широком диапазоне концентраций легирующих добавок. Проведено сравнительное испытание образцов сплава ВК-6, легированных ванадием, рением, изготовленных из сырья разной степени очистки на твердость по Роквеллу, износостойкость. Проведено их рентгеноструктурное исследование.

Образцы на основе сырья повышенной степени очистки (4 степени) изготовлены следующим образом. Изготовлено 4 пробы порошка $\mathrm{W}$ металлического из паравольфрамата аммония - продукта гидрометаллургического цеха полуфабрикатов вольфрама НПО ПРМиТС), по схеме переочистки:

1) ПВА-0: растворение ПВА-0 в азотной кислоте до получения вольфрамовой кислоты; фильтрация; промывка вольфрамовой кислоты до нейтрального значения $\mathrm{pH}$; фильтрация; растворение вольфрамовой кислоты в аммиачной воде; упарка раствора вольфрамата аммония; выделение кристаллов ПВА;

2) ПВА-1 - переочисткой ПВА-0;

3) ПВА-2 - переочисткой ПВА-1;

4) ПВА-3 - переочисткой ПВА-2;

Получение $\mathrm{W0}_{3}-\mathrm{O}, \mathrm{WO}_{3}-\mathrm{O}, \mathrm{WO}_{3}-1, \mathrm{WO}_{3}-2, \mathrm{WO}_{3}-3-1, \mathrm{WO} 3-2, \mathrm{WO}_{3}-3$ - прокалкой при 650-700 ${ }^{\circ} \mathrm{C}$ ПВА-0,ПВА-1,ПВА-2,ПВА-3; Получение порошков W металлического W-0, W-1, W-2, W-3 восстановлением $\mathrm{WO}_{3}-0, \mathrm{WO}_{3}-1, \mathrm{WO}_{3}-2, \mathrm{WO}_{3}-3$ в водородной среде. Полуфабрикаты WO3 -0, WO3 1, WO3 -2, WO3 -3 и W-0, W-1, W-2, W-3 проанализированы (табл. 2)

Таблица 1 Результаты физико-механических испытаний образцов из модифицированного ТС ВК-6

\begin{tabular}{|c|c|c|c|c|c|}
\hline \multirow{2}{*}{ образца } & \multicolumn{3}{|c|}{ Опытные образцы, состав, \% масс } & \multirow{2}{*}{$\begin{array}{l}\text { Твердос } \\
\text { ть HRA }\end{array}$} & \multirow{2}{*}{$\begin{array}{l}\Delta \text { износост } \\
\text { кости } \%\end{array}$} \\
\hline & $\mathrm{WC}$ & $\mathrm{Co}$ & $\operatorname{Re}$ & & \\
\hline \multicolumn{6}{|c|}{ Образцы по заданию №2 } \\
\hline 19 & 93 & 6 & 1 & 89,4 & 33,33 \\
\hline 20 & 89 & 6 & 5 & 89,0 & 38,46 \\
\hline 21 & 94 & 6 & 0 & 88,5 & \\
\hline 22 & 94 & 6 & 0 & 88,5 & \\
\hline № & \multicolumn{3}{|c|}{ Опытные образцы, состав, \% масс } & & \\
\hline образца & $\mathrm{WC}$ & $\mathrm{Co}$ & $\mathrm{VC}$ & HRA & \\
\hline \multicolumn{6}{|c|}{ Образцы по заданию №3 } \\
\hline 23 & 89 & 6 & 5 & 89,1 & 57 \\
\hline 24 & 94 & 6 & 0 & 88,7 & \\
\hline 25 & 89 & 6 & 5 & 89,3 & 0 \\
\hline 26 & 94 & 6 & 0 & 88,9 & \\
\hline 27 & 89 & 6 & 5 & 89,7 & 65,3 \\
\hline 28 & 94 & 6 & 0 & 89,3 & \\
\hline
\end{tabular}

Таблица 2 Результаты контроля чистоты проб полуфабрикатов в задании №3

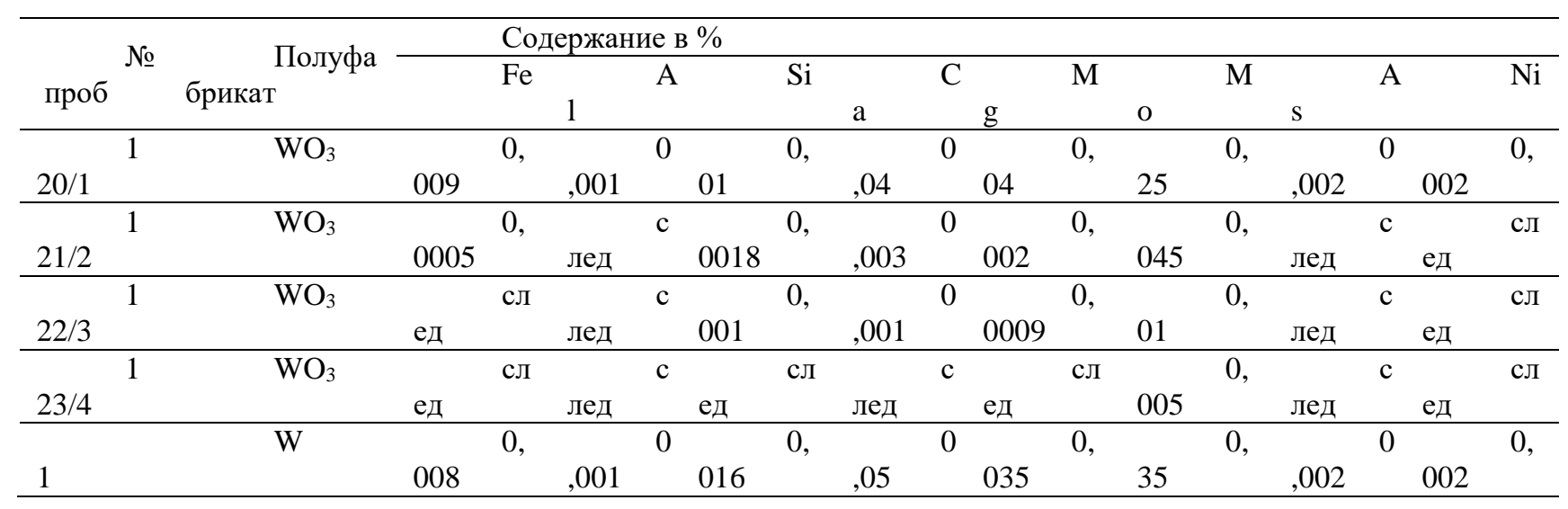




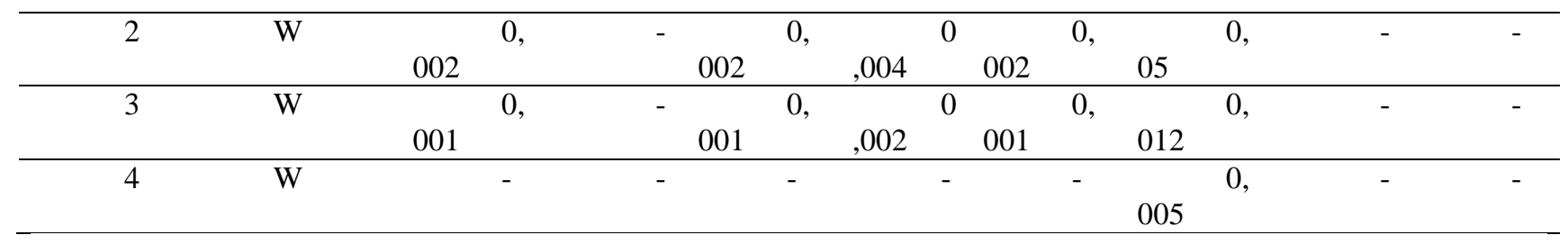

\section{Выводы}

1) Модифицированные ванадием твердые сплавы WC-VC-Co (в диапазоне концентрации карбида ванадия: от 1 до 16\% масс.), на примере сплава ВК-6, оказались, соответственно с ростом доли лигатуры, на $\approx 3 \%$ более твердыми и до $90 \%$ более стойкими к износу, по сравнению со сплавом BK-6 системы WC-Co, с равным содержанием кобальта. 2) Модифицированные рением твердые сплавы WC-ReC-Co (в диапазоне концентрации карбида рения: от 1 до 5\% масс.), на примере сплава ВК-6, оказались, соответственно с ростом доли лигатуры, на $\approx 3 \%$ более твердыми и на $35 \%$ более стойкими к износу, по сравнению со сплавом ВК-6 системы WC-Co, с равным содержанием кобальта. 3) Дополнительная очистка (перекристаллизацией) W-сырья твердого сплава WC-ReC-Co (при фиксированной концентрации карбида рения 5\% масс.), по сравнению со сплавами: «ВК-6» и «ВК-6модифицированный 5\% рения без дополнительной очистки», привела к росту сопротивления износу: с 38,5\% (сплав «ВК-6-модифицированный 5\% рения»), до 57,0\% (однократная) и 65,3\% (трехкратная очистка) сплава «ВК-6-модифицированный $5 \%$ рения с дополнительной очисткой», все относительно «ВК-6». 4) Проведенные опытно-промышленные испытания изделий - наплавок на токарные резцы из сплава ВК-6 с VC 3\% масс., выявили, что они оказались на 30-35\% более стойкими к износу, чем образцы из серийного сплава ВК-6, с равным содержанием кобальта; это означает увеличение ресурса работы инструмента на 30-35\%. Рекомендовать технологию легирования и очистки вольфрамового сырья к опытно-промышленному испытанию модифицированного сплава ВК-6.

Ссылка на данную статью: Рузиев У., Элназаров У., Гуро В. П. (2020) Легирование Твердых Сплавов Системы Карбид Вольфрама-Кобальт Ванадием и Рением Для Повышения Износостойкости. Материалы Международной практической интернет-конференции «Актуальные проблемы науки» [Challenges of Science]. Выпуск III, стр. 190-194. https://doi.org/10.31643/2020.029

\section{Литературы}

[1] Rasulova, S.N., Guro, V.P., Safarov, E.T., Adinaev, X.F. (2020). Metals recovery from molybdenite concentrate by electrooxidation and leaching. IOP Conf. Series: Materials Science and Engineering 848 (2020) 012076 IOP Publishing doi:10.1088/1757-899X/848/1/012076.

[2] du Randt, D., Luyckz, S., Marcoulides, D., Northrop, I.T. and Whitefield, D.J. (2000). A comparison between ultrafine WC -Co and fine WC-VC-Co alloys', Int. J. of Materials and Product Technology, Vol. 15, Nos 3/4/5, pp. 270-274.

\section{References}

[1] Rasulova, S.N., Guro, V.P., Safarov, E.T., Adinaev, X.F. (2020). Metals recovery from molybdenite concentrate by electrooxidation and leaching. IOP Conf. Series: Materials Science and Engineering 848 (2020) 012076 IOP Publishing doi:10.1088/1757-899X/848/1/012076. (In English).

[2] du Randt, D., Luyckz, S., Marcoulides, D., Northrop, I.T. and Whitefield, D.J. (2000). A comparison between ultrafine WC -Co and fine WC-VC-Co alloys', Int. J. of Materials and Product Technology, Vol. 15, Nos 3/4/5, pp. 270-274. (In English). 